\title{
ABOUT DIVERSITY CIRCULATION OF THE FETUS AND THE NEWBORN. LITERATURE REVIEW
}

\author{
CShkarin N., ORCID: 0000-0002-2186-7362, Mordovia State University, \\ Saransk, Russia, n.shkarin2018@gmail.com \\ CNaumenko E., M.D., Mordovia State University, \\ Saransk,Russia,ei-naumenko@yandex.ru
}

\section{ОБ ОСОБЕННОСТЯХ КРОВООБРАЩЕНИЯ ПЛОДА И НОВОРОЖДЕННОГО. ОБЗОР ЛИТЕРАТУРЫ}

\author{
СШкарин Н. С., ORCID: 0000-0002-2186-7362, Наџиональный исследовательский \\ Мордовский государственный университет им. Н.П. Огарева, \\ 2. Саранск, Россия, n.shkarin2018@gmail.com \\ (СНауменко Е. И., канд. мед. наук, Национальный исследовательский Мордовский \\ государственный университет им. Н.П. Огарева, \\ 2. Саранск, Россия, ei-naumenko@yandex.ru
}

Abstract. The article presents a modern understanding of the physiology of the fetal-placental circulation, reflects the characteristics of blood flow in the fetus and the newborn. The anatomical and physiological features of the cardiovascular system in newborns are covered in detail.

Аннотащия. В статье представлены современные представления о физиологии плодовоплацентарного кровообращения, отражены особенности кровотока у плода и у новорожденного. Детально освещены анатомо-физиологические особенности сердечнососудистой системы у новорожденных детей.

Keywords: blood circulation, fetal and placental circulation, fetus, newborn.

Ключевые слова: кровообращение, плодово-плацентарное кровообращение, плод, новорожденный.

At the earliest stages, the developing heart begins to provide the embryo with oxygen and nutrients [1, p. 471], and goes through a complex path of ontogenesis to achieve physiological characteristics. At the very beginning, the single-layer tube passes through a stage of non-compact trabecularity and is transformed into a multi-layer compact wall [2, p. 67]. Along with this differentiated electrical activity of myocardial cells. It is the finally formed architectonics of the heart that provides a quick and powerful shock to the blood flow that supports the volume of blood flow and the ability to be modified by changing the minute volume depending on the metabolic needs of organs and tissues [3, p. 125]. Looking ahead, it is worth mentioning that impaired fetal growth correlates with impaired heart development (the process of myocardial maturation continues after birth, so the pathology associated with fetal communication violates the function and structure of the heart).

The heart of a newborn is relatively large and amounts to $0.8 \%$ of body weight, which is slightly more than the similar ratio in adults $(0.4 \%)[4, \mathrm{p} .44]$. The right and left ventricles are approximately equal. The thickness of their walls is about $5 \mathrm{~mm}$. The atria and great vessels are somewhat larger than the ventricles [5, p. 734]. 
An increase in the mass and volume of the heart occurs most intensively during the first 2 years of life and in adolescence [5, p. 740].

In all periods of childhood, an increase in the volume of the heart lags behind the growth of the body as a whole. In addition, the parts of the heart increase unevenly: the atria grow more intensively up to 2 years [6].

The projection of the heart on the spinal column falls on the level between the IV and VIII thoracic vertebrae. The left edge of the heart extends beyond the midclavicular line, the right one extends beyond the edge of the sternum [5, p. 743].

The projection of the apex of the heart of a newborn is in the fourth intercostal space, by 1.5-2 years it is shifted to the fifth. The upper border of the heart gradually falls: in the first month of life from the level of the first intercostal space to the 2 nd rib, by 2 years it reaches the second intercostal space [1, p. 472].

Especially intensively grow the left heart. The stimulator of left ventricular growth is increasing vascular resistance and blood pressure. The mass of the right ventricle in the first months can decrease by almost $20 \%$, which is explained by a drop-in resistance in the lungs due to the arterial duct shutdown [6].

At the same time, tissue differentiation occurs. The myocardium in the newborn is an undifferentiated syncytium [7, p. 816]. Muscle fibers are very thin, poorly delimited from each other. Weakly expressed longitudinal fibrillation and transverse striation. A large number of small, undifferentiated nuclei. The connective and elastic tissue is poorly developed [8, p. 235].

The first 2 years of life, intensive growth and differentiation of the myocardium takes place: the thickness and the number of muscle fibers increase, the number of muscle cell nuclei decreases with a significant increase in their size [1, p 471; 4, p. 44]. Septal septa and cross striation, subendocardial layer appear. Reduction of muscle fibers and an increase in the diameter of cardiac conductive monocytes (Purkinje fibers) occur in the trunk of the heart.

Under the influence of the vagus nerve, the heart rhythm decreases and sinus arrhythmia (like the respiratory one) and individual 'vagal impulses' can appear — sharply extended intervals between cardiac contractions [9, p. 2054]. Reflex effects are carried out by interoreceptors of both the heart and other internal organs, which changes the frequency of the rhythm under the influence of various physiological factors [10, p. 73]. Such functions of the myocardium as automatism, excitability, conduction, contractility and toychest, are carried out in the same way as in adults. Coronary vessels up to 2 years are distributed on the loose [11, p. 424].

The lumen and wall thickness (due to intima) of the main vessels are increased, and the peripheral branches are reduced.

Abundant vascularization and friable fiber, surrounding vessels, create a predisposition to inflammatory and dystrophic changes of the myocardium. Sclerosis and myocardial infarction at an early age are very rare [12, p. 15].

At the time of birth, the main trunk of the pulmonary artery is relatively short and divides into two approximately equal branches, which creates pressure drops between the vessels (up to 8-15 $\mathrm{mm} \mathrm{Hg}$ ) in some children and may cause a characteristic systolic noise of the peripheral stenosis of the pulmonary artery [13, p. 86]. After birth, the lumen of the pulmonary artery does not initially increase, and the diameter of its branches grows rather intensively, which leads to the disappearance of the pressure drop, usually by 5-6 months [14, p. 1226]. The wall of the pulmonary artery consists of elastic fibers with smooth muscle elements. In response to hypoxia and acidosis, the arterial lumen may decrease significantly. In children of the first weeks and months of life, the muscular layer of the pulmonary vessels is less pronounced, which explains the smaller response of children to hypoxia. 
The length of the aorta before the bifurcation at the time of birth averages $125 \mathrm{~mm}$, the diameter of its exit is about $6 \mathrm{~mm}$. The same width is characteristic of the descending division. The aortic aperture, located at a distance of $10 \mathrm{~mm}$ from the site of the left subclavian artery, has an internal diameter of only about $4 \mathrm{~mm}$. During the first months of life, the mouth area expands, and after half a year, the narrowing of the lumen is no longer defined here.

The circumference of the pulmonary artery in children is greater than the circumference of the stem of the ascending aorta. The lumen of the arteries as a whole narrows somewhat with age relative to the size of the heart and the increasing length of the body.

The principal feature of the fetus is that the lungs do not take part in the oxygenation of the blood, they are filled with fluid and have high resistance to blood flow. The function of gas exchange is assigned to the placenta.

Oxygenated blood from the placenta along the umbilical vein and venous duct enters the inferior vena cava, but venous blood is also collected from the liver and the lower half of the body. The system of the superior vena cava collects venous blood from the upper half of the body and head.

Blood circulation in a single functional system mother-placenta-fetus is the leading factor ensuring the normal course of pregnancy, growth and development of the fetus. From the end of the second month of life, the fetus has its own blood circulation.

The stream of oxygenated blood from the placenta, through the umbilical vein on the surface of the liver is distributed in two directions: one enters the portal vein, bringing with it $50 \%$ of all blood, the other continuing the umbilical vein in the form of the Arantzia duct, flows into the inferior vena cava, where the placental blood mixed with venous blood from the pelvic organs, liver, intestines and lower extremities. The blood flowing through the hollow veins in the right atrium, is divided into two channels. The bulk of blood (60\%) from the inferior vena cava, due to the valve-shaped fold in the right atrium (Eustachian valve), enters through the oval window into the left atrium, left ventricle and aorta. The remaining blood from the inferior vena cava and the blood from the superior vena cava flows through the right atrium into the right ventricle and further into the pulmonary trunk.

This blood flows through the pulmonary artery into the non-functioning lungs and arterial (Botallov) duct, entering the descending part of the aorta below the site of the vessels that deliver blood to the brain [9, p. 2054].

Thus, a fundamental feature of the fetus is that the lungs are not involved in blood oxygenation, they are filled with fluid and have high resistance to blood flow. The function of gas exchange is performed by the placenta [1, p. 473].

Despite the fact that the partial pressure of oxygen $\left(\mathrm{pO}_{2}\right)$ in umbilical cord blood is almost two times lower than that of the mother $(55 \pm 7$ and $100 \pm 15 \mathrm{mmHg}$, respectively), fetal tissues receive sufficient oxygen through fetal hemoglobin (having increased ability to bind oxygen) and accelerated blood flow in the placental system [11, p. 62]. And one more characteristic feature of the intrauterine circulation is that the aorta and the pulmonary trunk receive mixed arteriovenous blood with approximately the same partial pressure of oxygen. At the same time, hemoglobin saturation with oxygen in the right and left ventricles differ slightly, amounting to about 50 and $60 \%$, respectively [11, p. 59].

An important aspect is the determination of the nature of the immaturity of the myocardium. However, the age limit at which the immature myocardium finally passes into the mature one is also unknown.

There is no doubt that the myocardium of a newborn has significant differences from the myocardium of an adult. In particular, in the heterogeneous population of cardiomyocytes of the 
newborn there are mainly undifferentiated cells with fewer myofibrils and mitochondria, poorly developed sarcoplasmic reticulum.

Undifferentiated cardiomyocytes receive energy through predominantly anaerobic processes. Almost all of the oxygen consumed by the left ventricle is consumed for the oxidation of glucose, lactate and pyruvate (there is a greater glycolytic activity than in adults).

Different mechanisms that reduce myocardium. In the immature myocardium, there is a lower concentration of intracellular calcium; changed reactions to it [3, p. 130]. A significant role in calcium metabolism, unlike adults, is played by sarcolemma. However, the SAR of the coplasmic reticulum is poorly developed, its ability to sequester calcium during relaxation and release during contraction is reduced, which leads to a decrease in the rate of shortening and relaxation of cardiomyocytes. To achieve maximum contractility in response to calcium, its greater external concentration is required compared with the adult heart.

Despite the immature myocardial vascular system, represented mainly by loose-type vessels, good blood flow and delivery of nutrients and oxygen to any point of the myocardium are provided with small intercapillary distances.

The features of the contractile myocardium of a newborn baby cause its smaller elasticity and inotropic activity than in older age. However, the limitations in the change in stroke volume are compensated by a rapid increase in heart rate in response to any stressful effect.

The process of myocardial maturation consists of the maturation of cardiomyocytes, connective tissue stroma, vascular network, and nerve elements. Differentiation of myocardial cells includes: 1) the formation of the contractile apparatus and intercalated disks, which is accompanied by an increase in the contractile properties of the heart muscle; 2) the formation of a specialized sarcoplasmic reticulum and channels of the T-system, leading to changes in calcium metabolism and more effective contractions; 3) differentiation of interfibrillar mitochondria with a change in the type of energy metabolism of cells, an increase in their respiratory activity and oxygen demand (that is, a transition to a more intensive aerobic metabolism).

Characteristic features of the neonatal myocardium, due to the specifics of energy and calcium metabolism of poorly differentiated cardiomyocytes, it is important to consider when treating patients in the first months of life. In particular, these differences in metabolism can determine the peculiarities of the reactions of the pediatric myocardium during cardiac surgery.

Adaptation of the blood circulation of a newborn child to extrauterine existence is defined as «transitional blood circulation» [14, p. 1230].

The formation of hemodynamics after the birth of a child is not a discontinuous restructuring of the functions performed by different parts of the heart. Significant changes in blood circulation occur in the first hours and days after the birth of a child [10, p. 74]: placental blood flow stops, blood flow increases in the pulmonary circulation, fetal communications are closed, effective pulmonary metabolism is becoming.

The formation of pulmonary blood flow due to a decrease in the resistance of pulmonary vessels. This is facilitated by mechanical expansion of the lungs, as well as significant factors in this process can be considered an increase in $\mathrm{pO}_{2}$ and a decrease in $\mathrm{pCO}_{2}$ in the blood. In the first hours of life, the pressure of blood in the pulmonary artery is equal to systemic blood pressure, and then it decreases to $30 \mathrm{~mm}$. Hg Art., which is about 1/2 of systemic blood pressure [11, p. 424].

Reorganization of intracardiac hemodynamics is carried out by closing fetal communications. In healthy newborns, the blood flow through the open oval window in $92 \%$ of cases continues to be registered during the first hour after birth, but it quickly decreases by 24 hours [12, p. 57].

Functional closure of an open oval window normally occurs in the first hours of life, when blood flow through the lungs increases to such a value that is necessary to maintain the blood 
pressure in the left atrium at a level greater than the pressure in the right atrium. Anatomic closure of an open oval window begins on the 5th - 7th day of life. In 50\% of healthy children, an open oval window may temporarily function from 8 days to 1 year of life.

The rest of the children have an open oval window open up to 5 years, and $25 \%$ have a lifelong lifespan [1]. With an imbalance in the development of various parts of the interatrial septum, valve incompetence and keeping the orifice open may occur [10, p. 78].

The reason for the persistent oval window up to adulthood is the incomplete fusion of the primary and secondary partitions with the remaining oblique splitting between the two atria [12, $\mathrm{p}$. 19].

The presence of an open oval window in children due to the severity of complications requires dynamic observation of the pediatrician, adequate treatment of intercurrent diseases, rehabilitation of chronic foci of infection and differential diagnosis with congenital heart defects: atrial septal defect [3, p. 138].

The functioning of the ductus arteriosus after birth is normal and may persist for several hours or days. The discharge of blood from right to left, common in the prenatal period, is significantly reduced after umbilical cord occlusion [12, p. 64]. As the general pulmonary pressure drops and pressure in the pulmonary artery arises, bidirectional and then mostly left-right blood flow through the open arterial duct arises. Its closure occurs in two stages: the primary functional closure associated with the contraction of smooth muscles in the duct wall, and the final closure, determined by the destruction of the endothelium, cell proliferation under the intima of the vessel and the formation of connective tissue [15, p. 11].

Functional closure of the arterial duct in most children occurs within 24 to 72 hours after birth. In $5 \%$ of healthy full-term newborns, the arterial duct normally closes within the first 7 hours after birth, 50\% within 21 hours and 95\% of infants within 65 hours [5, p. 740]. Anatomical obliteration of the duct occurs slowly, during 2-3 months of life, then the duct is transformed into a bundle in $90 \%$ of children by the end of the 3rd month of life. The phenomenon of intrauterine closure of the arterial duct has been described [7, p. 816].

Normally, the period of early postnatal adaptation, characterized by the closure of fetal communications, lasts approximately from several hours to several days. The functioning of the open arterial duct and the open oval window in a given period of time and the high resistance of the pulmonary vessels causes the presence of transient pulmonary hypertension in newborns [2, p. 87; 4, p. 52].

The open oval window is a fairly frequent state of the late neonatal period, diagnosed in $29.5 \%$ of children observed for congenital pathology of the cardiovascular system [2, p. 100]. Also, in the late neonatal period, the open arterial duct functions 2.5 times more often than in children in the subsequent age group [6].

The following main characteristics are characteristic of the late neonatal blood circulation [1, p. $471 ; 10$, p. 80]:

-placental blood flow is eliminated, descent of placental communications is noted;

-fetal communications do not function;

-the resistance of the pulmonary vascular bed progressively decreases and increases in the arterial bed (due to the loss of the placenta, which has low resistance). There is an increase in pulmonary blood flow;

-blood pressure in the output tract of the right ventricle and pulmonary artery is lower than systemic blood pressure;

-the ventricles of the heart work consistently, each of them individually pumps up half of the total cardiac output; 
-the speed of tricuspid and transmitral blood flow is about the same;

-there is a gradual increase in the tone of peripheral regulatory vessels and systemic blood pressure;

-decreases blood viscosity.

In the normal course of the postpartum process, cardiac output and oxygen consumption gradually decrease by the 6th week. Normal hemodynamic modes of operation of the ventricles are established - the right one, which pumps blood into the pulmonary vessels with relatively low resistance, and the left one, which forces blood into the great circulation with high vascular resistance [9, p. 2055].

It is also worth mentioning the period of transitional hemodynamic adaptation. During the period of transitional hemodynamic adaptation is influenced by many factors. the main ones are: an adverse course of pregnancy and childbirth, the gestational age of the child, the effect of pre-, intraand / or postnatal asphyxia, the maturity of the cardiovascular system. they lead to the persistence of fetal communications that maintain high pressure in the system of the pulmonary circulation $[2, \mathrm{p}$. 102; 9, p. 2057].

The course of pregnancy against the background of existing somatic and obstetric pathology is often complicated by placental insufficiency, leading to the development of miscarriage, chronic intrauterine hypoxia, intrauterine growth retardation, and birth asphyxia.

Of particular importance is the hypoxic-ischemic effect, which is a key etiopathogenetic factor in the development of a number of severe pathological conditions affecting both the child's body as a whole and the cardiovascular system in particular [6; 9, p. 2060].

Premature babies are most susceptible to the negative effects of hypoxia due to initial immaturity and inability to respond adequately to birth stress, which leads to a breakdown of adaptation reactions $[4$, p. $51 ; 5$, p. 741$]$.

In newborns with low and extremely low birth weight, postnatal restructuring of cardiac hemodynamics takes place with great tension, which is caused by the severity of the general condition, persistence of fetal communications, often combined, which creates an increased hemodynamic load on the cardiovascular system [3, p. 136].

In newborns who had features of the antenatal period, underwent hypoxia, operatively born, the processes of postnatal hemodynamic restructuring also proceed with great stress, which is manifested by the presence of transient pulmonary hypertension, persistence of fetal communications that creates an increased hemodynamic load on the cardiovascular system [11, $\mathrm{p}$. 425].

In the early neonatal period, an eukinetic variant of central hemodynamics is recorded in $60 \%$ of children, hyperkinetic - in $26.4 \%$ and hypokinetic - in $13.6 \%$ of newborns. The formation of the central hemodynamic regime is influenced by the diameter of the open arterial duct and the duration of its functioning [11, p. 429].

The cardiovascular system in the premature compared to other functional systems is relatively mature, as it is laid in the early stages of ontogenesis [3, p. 133]. However, premature babies have certain features that, on the one hand, are a way of adaptation in conditions of pronounced morphofunctional immaturity, and, on the other hand, predispose to the occurrence of a number of pathological conditions [2, p. 86]. The main criteria are: signs of diastolic dysfunction, impaired systolic function in the form of dilatation of the left ventricular cavity and a decrease in myocardial contractility, as well as a decrease in blood flow rates in the aorta and pulmonary artery, signs of pulmonary hypertension, prolonged autonomic imbalance. 


\section{References:}

1. Philip, J., Samraj, R. S., Lopez-Colon, D., Gonzalez-Peralta, R., Chandran, A., \& Bleiwies, M. S. (2018) Severe Direct Hyperbilirubinemia as a Consequence of Right Heart Failure in Congenital Heart Disease. World J Pediatr Congenit Heart Surg, 9(4), 470-474. https://doi.org/10.1177/2150135116640786

2. Galie, N., Humbert, M., \& Vachieryc, J.-L. (2015). 2015 ESC/ERS Guidelines for the diagnosis and treatment of pulmonary hypertension. European Heart Journal, 46, 903-975. https://doi.org/10.1183/13993003.01032-20155

3. Platt, J. L., West, L. J., Chinnock, R. E., \& Cascalho, M. (2018). Toward a solution for cardiac failure in the newborn. Xenotransplantation, 25(6), 124-138. https://doi.org/10.1111/xen.12479

4. Simonneau, G., Robbins, I., \& Beghetti, M. (2009). Updated clinical classification of pulmonary hypertension. Journal of the American College of Cardiology, 54(1), S43-S54. https://doi.org/10.1016/j.jacc.2009.04.012

5. Travis, W. D., Costabel, U., Hansell, D. M., King, Jr. T. E., Lynch, D. A., Nicholson, A. G., ..., \& Behr, J. (2013). An official American Thoracic Society/European Respiratory Society statement: update of the international multidisciplinary classification of the idiopathic interstitial pneumonias. American journal of respiratory and critical care medicine, 188(6), 733-748. https://doi.org/10.1164/rccm.201308-1483ST

6. Baiges, A., Turon, F., Simón-Talero, M., Tasayco, S., Bueno, J., Zekrini, K., Plessier, A., Franchi-Abella, S., Guerin, F., Mukund, A., Eapen, C. E., Goel, A., Shyamkumar,N. K., Coenen, S., De Gottardi, A., Majumdar, A., \& García-Pagán, Joan C. (2019). Congenital extrahepatic portosystemic shunts (Abernethy malformation): An international observational study. Hepatology, https://doi.org/10.1002/hep.30817

7. Bussman, N., \& El-Khuffash, A. F. (2018). What is the most efficacious pharmacological therapy for patent ductus arteriosus closure in premature infants? Irish Medical Journal, 111(9), 817. https://epubs.rcsi.ie/paedart/14

8. Murki, S., Singh, J., Khant, C., Dash, S. K., Oleti, T. P., Joy, P., \& Kabra, N. S. (2018). High-flow nasal cannula versus nasal continuous positive airway pressure for primary respiratory support in preterm infants with respiratory distress: a randomized controlled trial. Neonatology, 113(3), 235-241. https://doi.org/10.1159/000484400

9. Hockel, K., Diedler, J., Neunhoeffer, F., Heimberg, E., Nagel, C., \& Schuhmann, M. U. (2017). Time spent with impaired autoregulation is linked with outcome in severe infant/paediatric traumatic brain injury. Acta neurochirurgica, 159(11), 2053-2061. https://doi.org/10.1007/s00701017-3308-8

10. Prezioso, G., Giannini, C., \& Chiarelli, F. (2018). Effect of Thyroid Hormones on Neurons and Neurodevelopment. Hormone research in paediatrics, 90(2), 73-81. https://doi.org/10.1159/000492129

11. Muhari-Stark, E., \& Burckart, G. J. (2018). Glomerular filtration rate estimation formulas for pediatric and neonatal use. The Journal of Pediatric Pharmacology and Therapeutics, 23(6), 424-431. https://doi.org/10.5863/1551-6776-23.6.424

12. Fakhry Abdel Massih, A., Zahraa Hassan, F. A., El-Gammal, A., Tawfik, M., \& Nabil, D. (2019). The overlooked left ventricle in Persistent Pulmonary hypertension of the Newborn. The Journal of Maternal-Fetal \& Neonatal Medicine, $1, \quad 11$. https://doi.org/10.1080/14767058.2019.1598363

13. Sluiter, I., Kraemer, U., Rottier, R., Tibboel, D., \& Reiss, I. (2010). Pulmonary Vascular Disease in the Newborn From Pathophysiology to Therapeutic Strategies. In: Pulmonary Arterial 
Hypertension: Focusing on a Future: Enhancing and Extending Life, 10, 85-92. https://doi.org/10.3233/978-1-60750-609-6-85

14. Malowitz, J. R., Forsha, D. E., Smith, P. B., Cotton, C. M., Barke,r P. C., \& Tatum, G. H. (2015). Right ventricular echocardiographic indices predict poor outcomes in infants with persistent pulmonary hypertension of the newborn. Eur Heart J Cardiovasc Imaging, 16(11), 1224-1231. https://doi.org/10.1093/ehjci/jev071

15. Lankhaar, J. W., Westerhof, N., Faes, T. J., Marques, K. M., Marcus, J. T., Postmus, P. E., \& Vonk-Noordegraaf, A. (2006). Quantification of right ventricular afterload in patients with and without pulmonary hypertension. American Journal of Physiology-Heart and Circulatory Physiology, 291(4), H1731-H1737. https://doi.org/10.1152/ajpheart.00336.2006

\section{Список литературы:}

1. Philip J., Samraj R. S., Lopez-Colon D., Gonzalez-Peralta R., Chandran A., Bleiwies M. S. Severe Direct Hyperbilirubinemia as a Consequence of Right Heart Failure in Congenital Heart Disease // World J Pediatr Congenit Heart Surg. 2018. V. 9. №4. P. 470-474. https://doi.org/10.1177/2150135116640786

2. Galie N., Humbert M., Vachieryc J.-L. 2015 ESC/ERS Guidelines for the diagnosis and treatment of pulmonary hypertension // European Heart Journal. 2015. №46. P. 903-975. https://doi.org/10.1183/13993003.01032-20155

3. Platt J. L., West L. J., Chinnock R. E., Cascalho M. Toward a solution for cardiac failure in the newborn // Xenotransplantation. 2018. V. 25. №6. P. 124-138. https://doi.org/10.1111/xen.12479

4. Simonneau G., Robbins I., Beghetti M. Updated clinical classification of pulmonary hypertension // Journal of the American College of Cardiology. 2009. V. 54. №1. S43-S54. https://doi.org/10.1016/j.jacc.2009.04.012

5. Travis W. D., Costabel U., Hansell D. M., King Jr, T. E., Lynch D. A., Nicholson A. G., ... Behr J. An official American Thoracic Society/European Respiratory Society statement: update of the international multidisciplinary classification of the idiopathic interstitial pneumonias // American journal of respiratory and critical care medicine. 2013. V. 188. №6. P. 733-748. https://doi.org/10.1164/rccm.201308-1483ST

6. Baiges A., Turon F., Simón-Talero M., Tasayco S., Bueno J., Zekrini K., Plessier A., Franchi-Abella S., Guerin F., Mukund A., Eapen C. E., Goel A., Shyamkumar N. K., Coenen S., De Gottardi A., Majumdar A., García-Pagán Joan C. (2019). Congenital extrahepatic portosystemic shunts (Abernethy malformation): An international observational study. Hepatology, https://doi.org/10.1002/hep.30817

7. Bussman N., El-Khuffash A. F. What is the most efficacious pharmacological therapy for patent ductus arteriosus closure in premature infants? // Irish Medical Journal. 2018. V. 111. №9. P. 817. https://epubs.rcsi.ie/paedart/14

8. Murki S., Singh J., Khant C., Dash S. K., Oleti T. P., Joy P., Kabra N. S. High-flow nasal cannula versus nasal continuous positive airway pressure for primary respiratory support in preterm infants with respiratory distress: a randomized controlled trial // Neonatology. 2018. V. 113. №3. P. 235-241. https://doi.org/10.1159/000484400

9. Hockel K., Diedler J., Neunhoeffer F., Heimberg E., Nagel C., Schuhmann M. U. Time spent with impaired autoregulation is linked with outcome in severe infant/paediatric traumatic brain injury // Acta neurochirurgica. 2017. V. 159. №11. P. 2053-2061. https://doi.org/10.1007/s00701-017-3308-8 
10. Prezioso G., Giannini C., Chiarelli F. Effect of Thyroid Hormones on Neurons and Neurodevelopment // Hormone research in paediatrics. 2018. V. 90. №2. P. 73-81. https://doi.org/10.1159/000492129

11. Muhari-Stark E., Burckart G. J. Glomerular filtration rate estimation formulas for pediatric and neonatal use // The Journal of Pediatric Pharmacology and Therapeutics. 2018. V. 23. №6. P. 424-431. https://doi.org/10.5863/1551-6776-23.6.424

12. Fakhry Abdel Massih A., Zahraa Hassan F. A., El-Gammal A., Tawfik M., Nabil D. The overlooked left ventricle in Persistent Pulmonary hypertension of the Newborn // The Journal of Maternal-Fetal \& Neonatal Medicine. 2019. $\quad$ V. $\quad 1 . \quad$ P. 11. https://doi.org/10.1080/14767058.2019.1598363

13. Sluiter I., Kraemer U., Rottier R., Tibboel D., Reiss I. Pulmonary Vascular Disease in the Newborn From Pathophysiology to Therapeutic Strategies // Pulmonary Arterial Hypertension: Focusing on a Future: Enhancing and Extending Life. 2010. №10. P. 85-92. https://doi.org/10.3233/978-1-60750-609-6-85

14. Malowitz J. R., Forsha D. E., Smith P. B., Cotten C. M., Barker P.C., \& Tatum G. H. Right ventricular echocardiographic indices predict poor outcomes in infants with persistent pulmonary hypertension of the newborn // Eur Heart J Cardiovasc Imaging. 2015. V. 16. №11. P. 1224-1231. https://doi.org/10.1093/ehjci/jev071

15. Lankhaar J. W., Westerhof N., Faes T. J., Marques K. M., Marcus J. T., Postmus P. E., Vonk-Noordegraaf A. Quantification of right ventricular afterload in patients with and without pulmonary hypertension // American Journal of Physiology-Heart and Circulatory Physiology. 2006. V. 291. №4. P. H1731-H1737. https://doi.org/10.1152/ajpheart.00336.2006

Работа поступила

в редакичю 20.06.2019 г.
Принята к публикациии 24.06.2019 2.

Ссылка для циитирования:

Shkarin N., Naumenko E. About Diversity Circulation of the Fetus and the Newborn. Literature Review // Бюллетень науки и практики. 2019. Т. 5. №7. С. 47-55. https://doi.org/10.33619/2414-2948/44/05

Cite as (APA):

Shkarin, N., \& Naumenko, E. (2019). About Diversity Circulation of the Fetus and the Newborn. Literature Review. Bulletin of Science and Practice, 5(7), 47-55. https://doi.org/10.33619/2414-2948/44/05 